\title{
A SYSTEMATIC REVIEW ON THE MANAGEMENT OF OSSEOUS DEFECTS DURING DENTAL IMPLANT PLACEMENT
}

WI. Chai. A systematic review on the management of osseous defects during dental implant placement. Annal Dent Univ Malaya 2009; 16: 24-30.

\begin{abstract}
This systematic review focuses on the management of two types of osseous defects, i.e. dehiscence and fenestration that arise during the placement of dental implant in the edentulous area (delayed implant placement). A systematic online search of main database from 1975 to 2009 was made. Five randomised controlled trials have been identified based on the inclusion criteria. Different management procedures were identified, in which guided bone regeneration procedure was most commonly advocated. Resorbable and non-resorbable m'embranes were compared, in which resorbable membrane was preferred as it caused less complicatiQn of membrane exposure or risk of infection. The benefit of using bone substitute along with membrane in rypairing bony defects cannot be concluded.
\end{abstract}

Key words: dental implant; dehiscence; fenestration; systematic reJiew

\section{INTRODUCTION}

Dental implant treatment has become widely popular since the early 1980s. Osseointegration of implant determines the prognosis of the implant treatment. However, due to multiple factors such as poor quality bone, sûrgical procedures or dental implant design, quite frequently surgeons encounter osseous defects while placing the implants, resulting in exposl!re of the implant. Two types of osseous d fects;- i.e. dehiscence and fenestration can arise during the placement of dental implant in the edentulous area. Dehiscence defect refers to the exposure of the coronal part of implant, while fenestration refers to the exposure of the body of implant in which the coronal parl of the implant is stilled covered with bone. This complication ay happen during immediate implant placement into an extraction socket (1-3), or during implant placement in an edentulous area (healed extraction socket) (4-8), or from an inflammation or infection as in periimplantitis (9-12). This review will focus on osseous defects which occur during implant placement in the edentulous area, and exclude those osseous defects resulting from fresh extraction sockets or periimplantitis. There are still some controversial issues in managing the dehiscence or fenestration with regards to the indications for guided bone regeneration (GBR),
Revievv Article

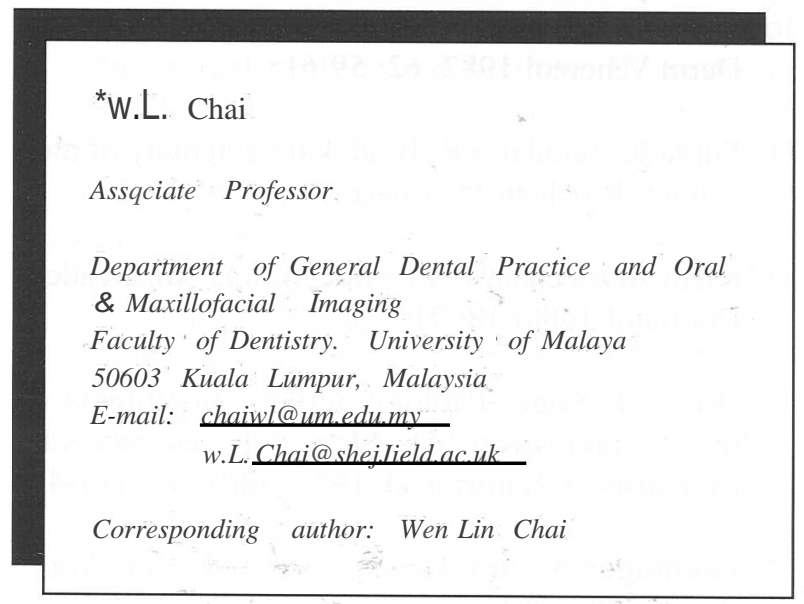

the use of resorbable or non-resorbable barrier and the need of bone filling materials.

\section{OBJECTIVE AND METHODS}

The aim of this review is to identify the most effective interventions for treating osseous defects namely dehiscence or fenestration that occur during dental implant placement in the edentulous area. Based on a conventional hierarchy of study designs, the highest evidence of study design, randomised controlled trials (RCT) were selected. This review excluded those interventions of osseous defects which occur during immediate implant placement into freshly extraction sockets or due to peri-implantitis as they are different in term of their aetiologies and thus influences bone regeneration mechanisms. Based on the search protocol recommended in Cochrane Handbook for Systematic Reviews of Interventions 5.0.1, a combination of controlled vocabulary and free text terms were used to identify relevant studies. Only English articles published since 1975 onward were selected, as the first dental implant study was published by the pioneer, PI Branemark only in 1977 (13).

\section{RESULTS}

Characteristics Of the trial setting and investigators

A total of 18 eligible trials were identified but only 5 trials (4-8) fulfilled the criteria of the review. The excluded 13 trials were due to: non-RCT trials $(14,15)$, inappropriate analyses as data were analysed on implant sites not on patient basis (1, 14-17), marginal defects which occur during immediate implant placement into extraction sockets (1-3, 18).

The five included trials were done in different countries, i.e. Sweden (4), the United Kingdom (5), the 
United States of America (New York) (6) and Switzerland (7, 8). Three trials used a split-mouth design and two trials used parallel group study design (6).

\section{Characteristics of the intervention}

The implant placements were all performed after the healing of extraction sites with a minimal of 6 week duration prio' (to implant placement. Dehiscence defects were mainly investigated $(5,7,8)$. Site of defects were or maxillary arch (4), mandibular arch (5) and both arches (7). No detailed information on the type of osseous defects and site of defects were reported in two trials $(6,8)$.

All trials used guided bone regeneration (GBR) technique as the main intervention technique to treat the defects. Two main types of barriers, i.e., nonresorbable barrier namely expanded polytetrafluoroethylene (e-PTFE) (Gore-Tex $\left.{ }^{\circledR}\right) \quad(5,6)$ and resorb able barrier such as Bio-absorbable collagen membrane (Bio-Gide $\left.{ }^{\circledR}\right) \quad(6,7)$ and synthetic bioresorbable polyethylene glycol (PEG) (8) were used. These barriers, except for PEG, were secured with either resorbable pins $(6-8)$, cover screws $(5,6)$ or beneath the flap (4).

All trials were completed at stage 2 surgery which was 5-7 months from the implant placement. All trials have $100 \%$ follow-up rate except one trial (7) which had one patient who withdrawn due to incomplete wound closure at the time of suture removal.

\section{Characteristics of the outcome measures}

Clinical outcomes as well as in-vitro analysis were used to evaluate the success of the interventions.

Reduction of bone defects (5-8), implant failure as well as the complications and side effects of intervention (6) were reported. In order to examine the quality of regenerated bone; -biopsies of the healing sites'were obtained for histomorphometric analysis $(5,7)$.

\section{Effects of interventions}

In total, 108 patients (one withdrew) with more than 94 implants (two implants were excluded due to the one withdrawal case) were obtained from these five trials. The exact number of implants was not able to be determined because in lung et al.'s article (2009), the number of implant treated was not reported clearly (8). Different surgical procedures were reported in treating dehiscence or fenestration which occurred during implant placement in the edentulous sites.

i) Is it necessary to use barrier to cover the osseous defect? (two trials)

Two trials compared the advantage of using barriers in GBR procedure to repair the osseous defects. Using split-mouth design, two trials compared the use and without the use of non-resorbable e-PTFE barrier (Gore- Tex, WL Gore and Associates, Inc., Flagstone, USA) around implants which have either fenestration (4) or dehiscence (5) during implant insertion. No bone filling materials were used as space maintainer (4, 5), but a small space was maintained over the exposed implant surface by manual convex shaping of the barrier (4). The barriers were either secured beneath the flap (4) or with cover screw (5) for 5-7 months $(4,5)$. In cases without barrier usage, the soft tissue flap was repositioned to cove the osseous defects. All implants placed were turned surface, screw-type, titanium self tapping Brfmemark (NoDeI Biocare, G6teborg, Sweden).

The results from both trials indicated that better reduction of defect size or bone gain was achieved when a barrier was used in GBR. However, there wasn't any statistical difference.

\section{ii) Resorbable versus non-resorbable barriers (one trial)}

A parallel-group design study compared the type of barrier used in GBR, i.e. resorbable porcine-derived collagen barrier (Bio-Gide, Geistlich Pharmaceutical, Wolhusen, Switzerland) versus non-resorbable e-PTFE barrier (Gore- Tex, WL Gore and Associates, Inc., Flagstone, USA) (6). n both groups, borie filling materials were used to support the overlaying barrier an'd to stimulate bone regeneration. The bone filling materials were made from mixture of bovine anorganic bone' (Bio-Oss, Geistlich Pharmaceljtical, Wolhusen, Switzerland)' and autogenous bone derived from the implant osteotomy sites in a ratio of $1: 1$. Both types of barriers were secured with either two polylactic acid bioabsorbable pins (Osseofix, Implant Innovations Inc., West Palm Beach, FL, USA or Resor-Pin, Geistlich Pharmaceutical, Wolhusen, Switzerland), or the implant cover screw, or the mucogingival flap. They were kept for 6 months.:All implants placed were turned surface, screw-type titanium (Implant Innovations Inc., West P:;t,lmBeach, Florida, USA).

There was no significant difference in the reduction of defect size in both groups. Both barriers were suitable to be used in guided bone regeneration. However, non-resorbable e-PTFE barrier have significant higher risk of membrane exposure during healing $(12.5 \%)$ versus resorbable collagen membrane $(8.7 \%)$.

A new synthetic hydrogel of polyethylene glycol (PEG) which is in a liquid form was compared to the standard collagen meml:5rane (BioGide) in one trial (8). In both groups, bone substitutes (BioOss) was used to graft the osseous defects. The result reveals that no statistical significant difference was observed in percentage of vertical defect fills.

iii) Is adding bone morphogenic protein into bone substitute mineral improve the GBR procedure? (one trial)

A split-mouth, placebo-control trial compared the effectiveness of recombinant human bone morphogenetic protein-2 (rhBMP-2; I ml of $0.5 \mathrm{mg}$ / 
$\mathrm{ml})$ versus placebo ( $1 \mathrm{ml}$ of $0.0 \mathrm{I} \%$ trifluoroacetic acid which is the solvent for rhBMP-2) on GBR (7). The bone morphogenic protein was mixed with bovine anorganic bone (Bio-Oss, Geistlich Pharmaceutical, Wolhusen, Switzerland) and covered with resorbable porcine-derived collagen barriers (Bio-Gide, Geistlich Pharmaceutical, Wolhusen, Switzerland) on implant sites which had mainly dehiscence defects. The barriers were secured using polylactic acid bioabsorbable pins (Resor-Pin, Geistlich P4armaceutical, Wolhusen, Switzerland) and kept for 6 months. All implants were turned surface, screw-type, Branemark implants (Nobel Biocare, G6teborg, Sweden).

There was a significant improvement in bone defects reduction when rhBMP-2 was added.

\section{DISCUSSION}

Systematic reviews on the management of bone defects in extraction sockets for implant placement (19) and peri-implantitis (20) are available. III this review, the author is only interested in reviewIng tria s on the intervention of a rather specific type of osseous defects, i.e. dehiscence or fenestration which happen during implant placement in thin edentulous area. In fact, this topic was reviewed in a systematic review in 2008 (19) but two additional trials $(5,8)$ are added into this review. The intervention of this type of defect may be differept from the bone regeneration in immediate impl§int placement in extraction sockets (1-3) or augmentation of the alveolar ridge prior to implant placement (21) or if the defects are due to periimplantitis (9-12, 22). For example, ifosseous defect is associated with peri-implantitis, the primary goal of management is to remove the bacteria around the implants. Different treatments such as smoothing the implant surface, decontamination of implant surface with chemical agents (11) or laser beam (12) have been suggested. The common goal of managing osseous defects related to peri-implantitis is by eliminati?n of the bacteria around implaiits first, then followed by resective procedure (9) or bone $\sim$ egen ative procedures (10, 22).

The highest form of study design was available for this review, i.e. the randomised controlled trials ( $\mathrm{RCls}$ ) which include parallel group and split-mouth designs; hence they were selected. Five trials were iaentified based on the inclusion criteria in this review. These trials vary slightly in term of the type of osseous defects for investigation, i.e. dehiscence $(5,8)$, fenestration (4) or both types of the defects $(6,7)$. Different interventions for bone regeneration around the def $\sim$ cts were used. The outcomes assessed in the trials varied too, with. some assessing clinical features such as the reduction of osseous defect size (5-7), while others assess the histomorphometric features $(5,7)$. Thus, with the presence of clinical and methodological heterogeneity in all the included trials, meta-analysis was not appropriate in this review. Nevertheless, all trials show good external validity, as the initial size of the defects equivalent to the majority dehiscence defect (23).

Meaningful estimate of effect from data can be achieved if the data from different trials were measured in the same way and have rather similar population profile. For example, if the population profile is similar, the effectiveness of interventions can be evaluate $\mathrm{d}$ from the outcome measure on the reduction of osseous defect size. In three trials which measure the reduction of defect sizes, the reduction unit used was in millimetre (5-8). The author would suggest that comparison of this outcome be more meaningful if the percentage $(\%)$ of defect size reduction was used as in Jung et a!.'s (8) report, due to the fact that the initial defect sizes vary in different trials.

Unfortuna ely, all trials did not provide a power calculation except one (8) and used rather small sample size, thus failed to demonstrate any significant difference between grpups. Another common methodological flaw during analysis of the outcome is that the unit of analysis was performeq on the implant rather than the patient $(1,14-17)$ in a split-mouth design. By using implant as unit of analysis, the patient factor was not taken into account as a confounding factor.

Without the use of barrier, it was suggested that the titanium oxide surface of the implant at the defect site will come into direct contact with the overlying periosteum connective tissue, instead of blood and bone. Thus, this cause limited bone formation over the defects (4). By using the barriers, it prevents the contact of periosteum onto the implant surface and allows osteogenesis on the defect sites. This feature was supported in animal model, where it was shown that when no bone filling materials were used to support the barriers, there would be complication of membrane collapse onto the implant surface and obstruct osteogenesis (24). In this review, no trials have investigated the indication of the bone filling materials during GBR. However, in other clinical trials, the group with bone allograft used concomitantly with either ePTFE (15) or resorbable collagen membrane (2) revealed higher success rate of full coverage of the defects than the use of barrier alone without bone filling materials, though no statistical difference was observed. Nevertheless, there was a disadvantage in using bone filling materials especially autogenous bone grafts. Even with careful precautIon in harvesting the autogenous bone grafts and use of antibiotic prophylaxis, bacteria contamination was still detected (25). Thus, the advantages of concomitant use of bone filling materials with barrier still require further well design trials to prove it.

The disadvantages of using non-resorbable e-PTFE (Gore Tex) are the need of second surgical procedure to remove the barrier and also higher risks of premature exposure and bacterial contamination $(6,16,26)$. In 
Table 1. Summary of five included trials

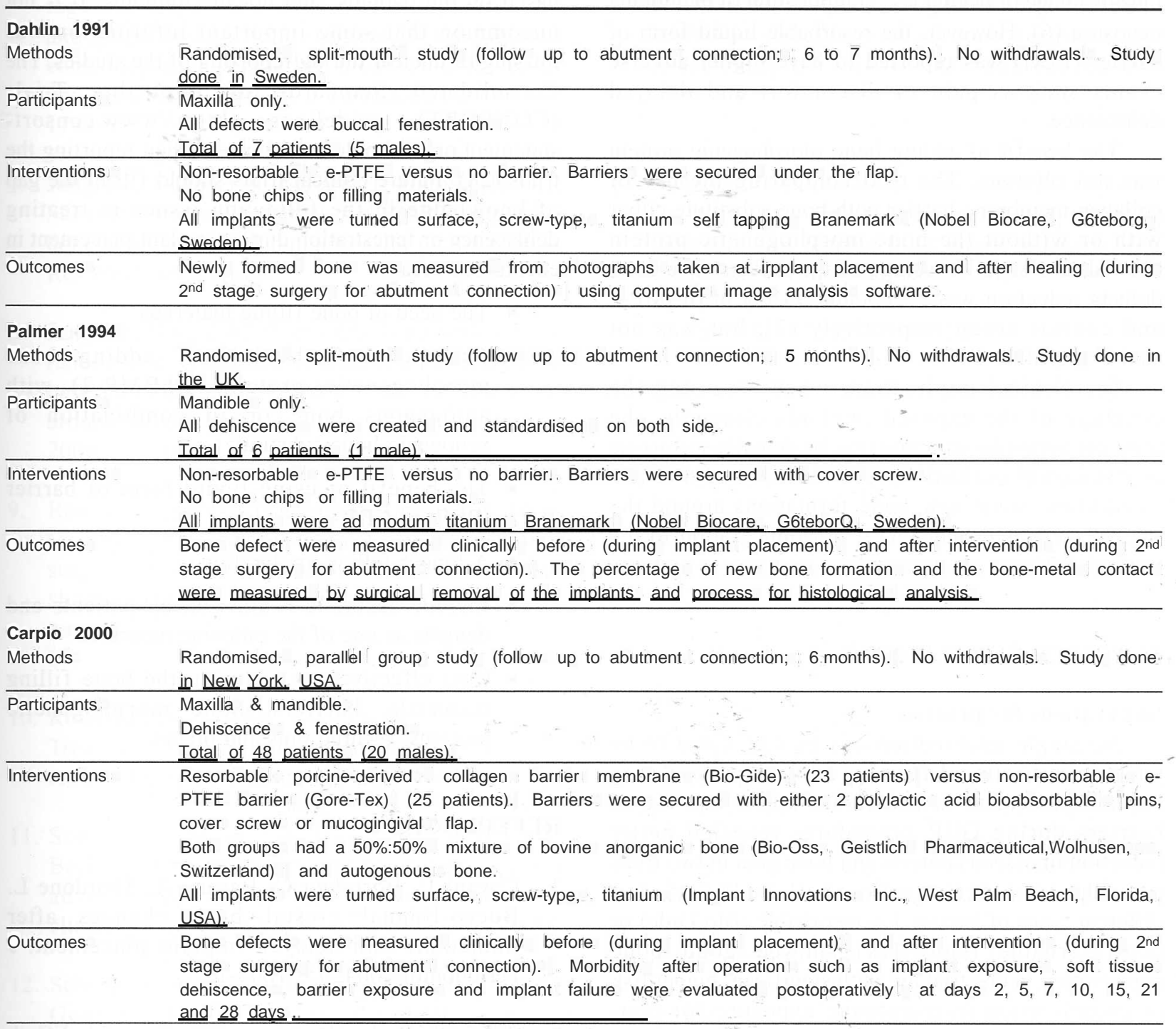

Jung 2003

Methods

Randomised split-mouth, placebo.:cootwlled study (follow up to abutment connection; 6 months). 1 patient was lost in follow up due to incomplete wouna? closure during suture removal stage after implant placement: Study done in Switzerland. .

\begin{tabular}{|c|c|}
\hline Participants & $\begin{array}{l}\text { Maxilla \& mandible. } \\
\text { Dehiscence (21 implants) \& fenestration (1 implant). } \\
\text { Total of } 11 \text { patients }(4 \text { males }) . \\
\text { Distance between test and control implants was at least } \underline{7} \underline{\mathrm{mm}} .\end{array}$ \\
\hline Inter & $\begin{array}{l}\text { Recombinant human bone morphogenetic protein-2 (rhBMP-2; } 1 \mathrm{ml} \text { of } 0.5 \mathrm{mg} / \mathrm{ml} \text { ) versus placebo (1 } \mathrm{ml} \text { of } \\
0.01 \% \text { triflouroacetic acid) on GBR using bovine anorganic bone (Bio-Oss) and. Barriers were secured with } \\
\text { resorbable polylactic acid pins. } \\
\text { All implants were turned surface, screw-type, titanium Mark II, III or IV Branemark implants (Nobel Biocare, } \\
\text { G6teborQ. Sweden). }\end{array}$ \\
\hline Outcomes & $\begin{array}{l}\text { Bone defects were measured clinically before (during implant placement) and after intervention (during } 2 \text { nd } \\
\text { stage surgery for abutment connection). } \\
\text { Post-operative complications such as implant or barrier exposure were recorded during healing period. } \\
\text { Cylindrical bone biopsies from aUomented areas were obtained for histomorohometric analysis. }\end{array}$ \\
\hline $\begin{array}{l}\text { Jung } 20 \\
\text { Methods }\end{array}$ & $\begin{array}{l}\text { Randomised, parallel-group study, controlled study (follow up to abutment connection; } 6 \text { months). Study done } \\
\text { in Switzerland. }\end{array}$ \\
\hline Participants & $\begin{array}{l}\text { Maxilla \& mandible. } \\
\text { Dehiscence only. } \\
\text { Total of } \underline{37} \text { patients Defect heiQht was } \simeq 3 \mathrm{~mm}\end{array}$ \\
\hline Interventions & 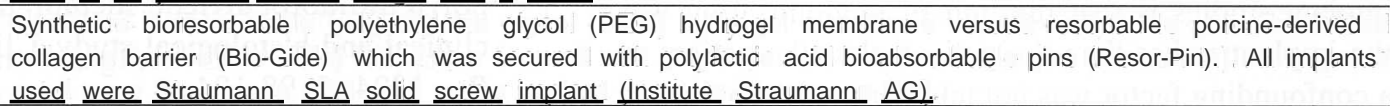 \\
\hline Outcomes & $\begin{array}{l}\text { Bone defects were measured clinically before (during implant placement) and after intervention (during } 2^{\text {nd }} \\
\text { stage surgery for abutment connection). Times taken for the procedures were compared. }\end{array}$ \\
\hline
\end{tabular}


contrast, resorbable collagen membrane (BioGide) has the advantage of having less complication of membrane exposure (6). However, the resorbable liquid form of barrier - (PEG) was reported to have higher adverse events such as pain or discomfort and delayed dehiscence.

The benefit of adding bone morphogenic protein was not obvious. The trial comparing the use of collagen membrane barrier with bone substitute either with or without the bone morphogenetic protfin showed almost full coverage of the defects. The bone defects reduction was $97.1 \%$ and $93.1 \%$ in rhBMP-2 and control group respectively (7), but was not statistically different.

For clinical implication, when assessing the coverage of the exposed implants clinically, the apparent bone-like structure may be actually soft tissue in histological evaluation, as evident in one trial (5). In addition, some new bone formations around the implant defects do not reveal osseointegration to the implant '(27).

\section{AUTHOR'S CONCLUSIONS}

\section{Implications for practice}

No single intervention can be concluded to be effective in treating dehiscence or fenestration during implant placement in edentulous areas. The use $9 \mathrm{f}$ barriers during GBR procedures revealed better reduction in o seous defects and bon'e gain in tw trials but without statistical significance $(4,>5)$. Both the two different types of barrier, i.e. resorbable (Bio-Gide) or non-resorbable (Gore- T.ex) showed good bone regeneration in one trial but with significant higher risk of complication in membrane exposure for nonresorbable barriers (6). The barriers need to be secured to avoid any movement which ma):' affect the bone regeneration process underneath the barriers. The new synthetic liquid form barrier (PEG) may have the advantage of needing less preparation time when compared to the standard collagen membrant $<$, but the benefit of it in GBR still need fl1rther-exploration.

\section{Implications for research}

More well-designed RCTs should be conducted in this area. Most available trials fail to provide significa $\sim$ difference between interventions. This could be due to: i) too few patients can be included in the trials, ii) in a9tual fact there aren't any differences among the tested groups. In general, larger sample size obtained from power calculation will help detecting the effectiveness of various interventions. Well-design multicentre trials will help solving the problem of lack of patients. One common' methodological flaw found in most dental implant studies is that the unit of randomisation was the implant rather than the patient, thus the patient as a confounding factor was not taken into account during statistical analysis. The statistical analysis should be based on the patients, and not the implants. It is not uncommon that some important information was missing or unclear dưring reporting of the studies. The Consolidated Standards of Reporting Trials (CONSORT) guidelines http://www.consortstatement.org/) should be followed when reporting the trials (28). Future clinical trials should fill in the gap of knowledge in the following issues in treating dehiscence or fenestration during implant placement in edentulous areas:

- The need of bone filling materials

- The potential benefit of adding bone morphogenetic proteins (rhBMP-2) with autogenous bone or in combination of xenogenic bone substitute

- The ben efit of using liquid form of barrier $(\mathrm{PE}<; \mathrm{T})$ in GBR

- A longer follow-up duration

- Include aesthetic" evaluation by patients and dentists as one of the outcome measures

- Cost effectiveness on using the bone filling materials, barriers, bone morphogenetic proteins, secured pins and others.

\section{REFERENCES}

I. Covani U, Bortolaia C, Barone A, Sbordone L. BU'cco-lingual crestal bone changes after immediate and delayed implant placement. ., J Periodontol 2004; 75: 1605-12.

2, Chen ST, Darby 1B, Adams GG, Reynolds EC. A prospective clinical study of bone augmentation techniques at immediate implants. Clin Oral Implants Res 2005; 16: 176-84.

3. Chen ST, Darby 1B, Reynolds Ee. A prospective clinical study of non-submerged immediate implants: clinical outcomes and esthetic results. Clin Oral Implants Res 2007; 18: 552-62.

4. Dahlin C, Andersson L, Linde A. Bone augmentation - at fenestrated implants by an osteopromotive membrane $\mathrm{t} \sim$ chnique. A controlled clinical study. Clin Oral Implants.Res 1991; 2: 15965 .

5. Palmer RM, Floyd PD, Palmer PJ, Smith BJ, Johansson CB, Albrektsson T. Healing of implant dehiscence defects with and without expanded polytetrafluoroethylene membranes: a controlled clinical and histological study. Clin Oral Implants Res 1994; 5: 98-104. 
6. Carpio L, Loza J, Lynch S, Genco R. Guided bone regeneration around endosseous implants with anorganic bovine bone mineral. A randomized controlled trial comparing bioabsorbable versus non-resorbable barriers. J Periodontol 2000; 71: 1743-9.

7. Jung RE, Glauser R, Scharer $\mathrm{P}$, Hammerle $\mathrm{CH}$, Sailer HF, Weber FE. Effect o rhBMP-2 on guided bone regeneration in humans. Clin Oral Implants Res 2003; 14: 556-68.

8. Jung RE, Halg GA, Thoma DS, Hammerle CH. A randomized, controlled clinical trial to evaluate a new membrane for guided bone regeneration around dental implants. Clin Oral Implants Res 2009; 20: 162-8.

9. Romeo E, Lops D, Chiapasco M, Ghisolfi M, Vogel G. Therapy of peri-implantitis with resective surgery. A 3-year clinical trial on rough screwshaped oral implants. Part II: radiographic outcome. Clin Oral Implants Res 2007; 18: 17987.

10. Roos-Jansaker AM, Renvert S, Egelberg 1 Treatment of peri-implant infections; a literature review. J Clin Periodontol 2003; 30: 467-85.

11. Schwarz F, Bieling $\mathrm{K}$, Bonsmann M, Latz $\mathrm{T}$, Becker J. Nonsurgical treatment of moderate and advanced periimplantitis lesions: a controlled clinical study. Clin Oral Investig 2006; 10: 279-88.

12. Schwarz F, Sculean A, Rothamel D, Schwenzer K, Georg T, Becker 1. Clinical evaluation of an Er: YAG laser for nonsurgical treatment of peri implantitis: a pilot study. Clin Oral Implants Res $2005 ; 16: 44-51$.

13. Branemark PI, Hansson BO, fldell R, Breine D, Lindstrom $\mathrm{J}$, Hallen $\mathrm{O}$, et al. Osseointegrated implants in the treatment of the edentulous jaw. Experience from a 10-year period. Scand J Plast Reconstr Surg SuppI1977; : 16; 1-132.

14. Dahlin C, Lekholm D, Becker W, Becker B, Higuchi K, Callens A, et al. Treatment of fenestration and dehiscence bone de(ects around oral implants using the guided tissue regeneration technique: a prospective multicenter study. Int J Oral Maxillofac Implants 1995; 10: 312-8.

15. Mattout P, Nowzari H, Mattout C. Clinical evaluation of guided bone regeneration at exposed parts of Branemark dental implants with and without bone allograft. Clin Oral Implants Res 1995; 6: 189-95.
16. Zitzmann ND, Naef R, Scharer P. Resorbable versus nonresorbable membranes in combination with Bio-Oss for guided bone regeneration. [erratum appears in Int J Oral Maxillofac Implants 1998 Jul-Aug;13(4):576]. Int J Oral. Maxillofac Implants $1997 ; 12: 844-52$.

17. Majzoub Z, Cordioli G, Aramouni PK, Vigolo P, Piattelli A. Guided bone regeneration using demineralized laminar bone sheets versus GTAM membranes in the treatment of implant-associated defects. A clinical and histological study. Clin Oral Implants Res 1999; 10: 406-14.

18. Cangini F, Cornelini R. A comparison between enamel matrix derivative and a bioabsorbable membrane to enhance healing around transmucosal iriullediate post-eX'traction implants. J Periodontol 2005; 76: 1785-92.

19. Esposito M, Grusovin MG, Kwan S, Worthington HV, Coufthard P. Interventions for replacing missing teeth: bone augmentation techniques for dental implant treatment. Cochrane Database Syst Rev 2008: CD003607.

20. Esposito M, Grusovin MG, Kakisis I, Coulthard P, Worthington HV Interventions for $\mathrm{r} \sim$ placing missing teeth: treatment of perimplantitis. Cochrane Database Syst Rev 2008: CD004970.

21. Chiapasco M, Romeo E, Casentini P, Rimondini L. Alveolar distraction osteogenesis vs. vertical guided bone regeneration for the correction of vertically deficient edentulous ridges: a 1-3-year prospective study on humans. Clin Oral Implants Res 2004 15: 82-95.

22. Schou. S, Berglundh T, Lang NP. Surgical,treatment of peri-implantitis. Int J Oral Maxillofac Implants 2004; 19 Suppl: 140-9.

23. Jovanovic SA, Spiekermann H, Richter EJ. Bone regeneration around titanium dental implants in dehisced defect sites: a clinical study. Int J Oral Maxillofac Implants 1992; 7: 233-45.

24. Dahlin C, Alberius P, Linde A. Osteopromotion for cranioplasty. An experimental study in rats using a membrane technique. J Neurosurg 1991; 74: 487 91.

25. Young MP, Carter DH, Worthington H, Karachi M, Drucker DB. Microbial analysis of bone collected during implant surgery: a clinical and laboratory study. Clin Oral Implants Res 2001; 12: 95-10B. 
26. Becker W, Dahlin C, Becker BE, Lekholm U, van Steenberghe D, Higuchi K, et al. The use of ePTFE barrier membranes for bone promotion around titanium implants placed into extraction sockets: a prospective multicenter study. Int J Oral Maxillofac Implants 1994; 9: 31-40.

27. Wachtel HC, Langford A, Bernimoulin JP, Reichart P. Guided bone regeneration next to osseointegrated implants in humans. Int $\mathrm{J}$ Oral Maxillofac Implants '1991; 6: 127-35.
28. Moher D, Schulz KF', Altman DG. The CONSORT statement: revised recommendations for improving the quality of reports of parallel-group randomised trials. Lancet 2001; 357: 1191-4. 